\title{
Average outgoing quality of calibration Lab facilities
}

\author{
M.A. Al Reeshi ${ }^{1}$ and Q. Yang ${ }^{2, \star}$ \\ 1 METCAL, BAE Systems SA, P.O. Box 98, 31932 Dhahran, Saudi Arabia \\ 2 School of Engineering and Design, Brunel University, Uxbridge, Middlesex UB8 3PH, UK
}

Received: 29 June 2013 / Accepted: 19 July 2013

\begin{abstract}
Quality assurance is an integrated part of any calibration facility. The calibration facility as well as its customers are interested in the facility production outgoing quality. In most calibration labs the inspection of calibrated items is performed according to a suitable sampling inspection policy. Some of these policies are very good in assuring the quality of the calibration services they offer, but do not provide a clear assessment of the outgoing quality of the entire production of the facility. This paper has developed two methods of calculating the average outgoing quality (AOQ) of a calibration lab that uses a multistage sampling inspection policy. The policy structure is presented first along with the exact procedure of how to perform it by the inspectors and the methods to calculate the AOQ. The two methods differ from each another in the type of data required to calculate the AOQ. The first method requires the technicians' production, the number of items subject to inspections and the number of failing items found. The second method requires only the number of technicians at each level of the multistage inspection policy. The verifications of the performances of two methods are accomplished by building a simulation model on an Excel worksheet. The model simulates the calibration facility with the right parameters, and then compares the two methods with the actual AOQ. The paper further discusses the advantages and disadvantages of each method in a broader context of quality assurance.
\end{abstract}

Keywords: Calibration; average outgoing quality; inspection policy; quality verification inspection

\section{Introduction}

Quality control and quality assurance is an integrated part of the calibration facility operations. The main objective of any production facility is to offer the customer defectfree products if they can, or more practically, produced items with only few defects. This can be done when the calibration facility has a means by which they can assess their average outgoing quality (AOQ), i.e. the percentage of the items that leaves the system with correct calibration from amongst all the received items. The assessment of the correct AOQ is not an easy matter and sometimes it can be extremely difficult. In the context of this research the calibration facility is assumed to have an inspection policy that monitors the performance of every technician without having to inspect every task performed. The reason for that is quite obvious, as it is easy to assess the AOQ if you perform a $100 \%$ inspection (in which case you would know exactly the percentage of defective items).

Jamkhaneh and Gildeh [1] introduced the AOQ and average total inspected (ATI) for double sampling plan when that proportion nonconforming items is a fuzzy number. Farnum [2] derived upper and lower bounds at the point at which the average outgoing quality limit (AOQL) of an attributes acceptance sampling plan is achieved. He developed an accurate closed-form approximation to

^ Correspondence: Ping.Yang@brunel.ac.uk the AOQL using a simple average of these bounds to approximate the ordinate of the AOQL. Balamurali and Jun [3] used the renewal theory approach to compute AOQ and AFI (average fraction inspected) for both long run and short run production processes. Yu and $\mathrm{Yu}$ [4] dealt with the problem of determining the optimal mixed policy of inspection and burn-in, where the AOQ is used as a measure of inspection and burn-in success. Yang [5] formulated a class of continuous sampling plans (CSPs) that switch between full and partial inspection of items in a production line in terms of discrete renewal processes. The renewaltheory framework facilitates studying both the long-run AOQ and the average outgoing quality in a short production run of length $t, \operatorname{AOQ}(t)$. Yang [6] used a sampling system, MIL-STD-105D, in quality control, which consists of three sampling plans with different acceptance probabilities in turn for lot inspection. They derived the performance measure, AOQ, of this sampling system from a renewal process in which AOQ is expressed in terms of the moments of the stopping times. Yeh et al. [7] examined a multi-characteristic screening procedure using multiple screening variables. An extended OMS procedure using a heuristic algorithm was employed to reach the required AOQ or conforming rate. Then two optimal models, namely the individual cut and linear cut approaches, were proposed to determine the optimal cutoff points of screening variables by maximizing the selected rate under 
a pre-specified AOQ or conforming rate. Moskowitz and Tsai [8] developed a double-screening procedure (DSP), which controls for individual unit misclassification error and AOQ for QC applications. Assuming conditions of normality, formulas for calculating the selection ratio and AOQ were derived for a DSP. Fard and Kim [9] presented the impact of imperfect inspection on AOQ, sample size, and operating characteristic (OC) curves for a 2-stage sampling plan.

The paper will first generally describe the problem and then detail the multistage inspection policy used, followed by the solution scheme and the two methods of computing the AOQ. The two methods are further verified by a simulation and compared in terms of their closeness to the actual AOQ and their usefulness.

\section{Description of the calibration facility operation}

Test measurement and diagnostic equipment (TMDE) arrives at the laboratory, booked in the system, gets calibrated by a technician and then dispatched to the user. The calibration assures the quality of measurement of the device, but that is done only when the calibration is performed correctly. Therefore, the facility must have a policy by which the item is assured the right calibration. This assurance is necessary, because the user has no way of checking the correctness of the calibration performed on the item (otherwise he would have calibrated it himself). Therefore, in order to assure the quality the items must be inspected for correct calibration. If the inspector finds any problem with it, the item is returned back to the technician to repeat the calibration, otherwise the item is dispatched to the user.

The inspection of the items can be performed in many ways ranging from the $100 \%$ inspection to sampling inspection. Laboratories usually adopt one of the many inspection policies available in the literature. Some inspection policy gives the management more control over some aspect of the quality than another policy, but the most important quality parameter, however, is the AOQ of the lab production.

Since $100 \%$ inspection is very costly for medium to large calibration facility, the other practical alternative is to adopt a sampling inspection policy. The objective of the lab is then focused on finding the portion of the defective items that have left the facility and already with the customers. The action would then be to correct the production directly so that the number of defective items is reduced right from the lab, not through the inspection. In other words the inspection must be used as an indication of the bad quality not as a correction to it.

In a short term, the assessed AOQ will become a characteristic of the lab and it will remain as such until a real change on the process or the methods of the calibration is performed. The AOQ will also be the monitor for the facility performance as a whole as well as the first warning to the management of any newly developed bad production streak that can occur suddenly for various reasons.

\section{Inspection policy}

The inspection policy under consideration is designed to inspect only a portion of the entire production. The outcome of the inspection is then used to draw some conclusions that will assess certain production decisions. The policy is designed to select the inspection based on the likelihood of the item failures. This is accomplished by increasing the inspection rate for those technicians who are more likely to produce defective items. The inspection rate is gradually increased or decreased based on the current performance of the technician. The policy is a four-stage policy that starts with the technician at level four (for new technicians who have just qualified, the starting point is at level 0). At level four, $6.25 \%$ of all the technician production is inspected. If no defect is found, he will stay at the level, otherwise he goes into various states that either brings him back to his current level or move him down one stage. At stage three, $12.5 \%$ of the production is inspected, and the same is done as the previous stage. At stage two the inspection rate is $25 \%$ and at stage 1 the inspection rate is $50 \%$. At stage zero the inspection rate is $100 \%$ and if there is any failure found in his first 18 jobs the technician is withdrawn from calibration work and given further training or re-assigned. The detailed inspection policy is shown in Figure 1. Once this inspection policy is applied the system will have an average outgoing quality level associated with it. The determination of this AOQ level is the problem that will be treated in this paper.

\section{$4 \mathrm{AOQ}$ problem and solutions}

AOQ problem can be stated as: given a specific inspection plan and a number of technicians, each of them is able to produce a number of items in the time interval chosen by the inspection policy. Find the average outgoing quality of the calibration facility.

The solution will start by developing the analytical solution of the methods that will be used to assess the AOQ of the calibration lab. The developed formulae will be verified by comparing them with the actual AOQ of the production facility. The comparison will be performed using a simulation model constructed in an Excel worksheet.

\section{Notation:}

$L: \quad$ Level of the technician which indicates the sampling rate for the technician (levels go from 0-4).

$C: \quad$ Number of technicians.

$R_{j}$ : $\quad$ Failure rate of technician $j$.

$P_{j}$ : $\quad$ Production of technician $j$.

$P_{L i}$ : Production of technician $i$ at level $L$.

$T$ : Total production that is subject to inspection.

$X_{L}$ : Average production of technicians at level $L$.

$X: \quad$ Average production of technicians.

$F_{i}$ : $\quad$ Failures from technician $i$ (actual).

$S: \quad$ Inspection rate $\%$ for each level. 


\begin{tabular}{|c|c|c|}
\hline \multicolumn{2}{|c|}{ Multilevel inspection policy } & \multirow{2}{*}{$\begin{array}{l}\text { Begin here } \\
\text { State } 4 \mathrm{R}\end{array}$} \\
\hline 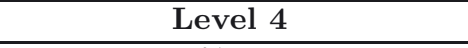 & $\begin{array}{c}\text { State } 4^{*} \\
\end{array}$ & \\
\hline $\begin{array}{l}\text { Inspect } 6.25 \% \text { of all certified } \\
\text { production by technician. }\end{array}$ & $\begin{array}{l}\text { Inspect } 6.25 \% \text { of all certified } \\
\text { production by technician. }\end{array}$ & $\begin{array}{l}\text { Inspect the next four items } \\
\text { certified by technician. }\end{array}$ \\
\hline $\begin{array}{l}\text { If a defect is found, } \\
\text { shift to State } 4 \mathrm{R} .\end{array}$ & $\begin{array}{c}\text { When } 14 \text { consecutive items } \\
\text { pass inspection, shift to Level } 4 .\end{array}$ & $\begin{array}{c}\text { If the next four items } \\
\text { pass inspection, shift to State } 4^{*} \text {. }\end{array}$ \\
\hline & $\begin{array}{l}\text { If a defect is found, } \\
\text { shift to State 3R. }\end{array}$ & $\begin{array}{l}\text { If a defect is found before four items } \\
\text { pass inspection, shift to State 3R. }\end{array}$ \\
\hline $\begin{array}{r}\text { Level } 3 \\
\end{array}$ & State $3^{*}$ & $\begin{array}{c}\text { State } 3 R \\
\end{array}$ \\
\hline $\begin{array}{l}\text { Inspect } 12.5 \% \text { of all certified } \\
\text { production by technician. }\end{array}$ & $\begin{array}{l}\text { Inspect } 12.5 \% \text { of all certified } \\
\text { production by technician. }\end{array}$ & $\begin{array}{l}\text { Inspect the next four items } \\
\text { certified by technician. }\end{array}$ \\
\hline $\begin{array}{l}\text { When } 18 \text { consecutive items pass } \\
\text { inspection, shift to Level } 4 .\end{array}$ & $\begin{array}{l}\text { When } 14 \text { consecutive items pass } \\
\text { inspection, shift to Level } 4 .\end{array}$ & $\begin{array}{l}\text { If the next four items pass } \\
\text { inspection, shift to State } 3^{*} \text {. }\end{array}$ \\
\hline $\begin{array}{l}\text { If a defect is found, } \\
\text { shift to State 3R. }\end{array}$ & $\begin{array}{l}\text { If a defect is found, } \\
\text { shift to State } 2 \mathrm{R} \text {. }\end{array}$ & $\begin{array}{l}\text { If a defect is found before four items } \\
\text { pass inspection, shift to State } 2 \mathrm{R} \text {. }\end{array}$ \\
\hline $\begin{array}{c}\text { Level } 2 \\
\end{array}$ & State $2^{*}$ & $\begin{array}{c}\text { State } 2 \mathrm{R} \\
\end{array}$ \\
\hline $\begin{array}{l}\text { Inspect } 25 \% \text { of all certified } \\
\text { production by technician. }\end{array}$ & $\begin{array}{l}\text { Inspect } 25 \% \text { of all certified } \\
\text { production by technician. }\end{array}$ & $\begin{array}{l}\text { Inspect the next four items } \\
\text { certified by technician. }\end{array}$ \\
\hline $\begin{array}{l}\text { When } 18 \text { consecutive items pass } \\
\text { inspection, shift to Level } 3 .\end{array}$ & $\begin{array}{l}\text { When } 14 \text { consecutive items pass } \\
\text { inspection, shift to Level } 3 .\end{array}$ & $\begin{array}{l}\text { If the next four items pass } \\
\text { inspection, shift to State } 2^{*} \text {. }\end{array}$ \\
\hline $\begin{array}{l}\text { If a defect is found, } \\
\text { shift to State } 2 \mathrm{R} \text {. }\end{array}$ & $\begin{array}{l}\text { If a defect is found, } \\
\text { shift to State 1R. }\end{array}$ & $\begin{array}{l}\text { If a defect is found before four items } \\
\text { pass inspection, shift to State 1R. }\end{array}$ \\
\hline $\begin{array}{c}\text { Level } 1 \\
\end{array}$ & State $1^{*}$ & State 1R \\
\hline $\begin{array}{c}\text { Inspect } 50 \% \text { of all certified } \\
\text { production by technician. }\end{array}$ & $\begin{array}{l}\text { Inspect } 50 \% \text { of all certified } \\
\text { production by technician. }\end{array}$ & $\begin{array}{c}\text { Inspect the next four items } \\
\text { certified by technician. }\end{array}$ \\
\hline $\begin{array}{l}\text { When } 18 \text { consecutive items pass } \\
\text { inspection, shift to Level } 2 .\end{array}$ & $\begin{array}{l}\text { When } 14 \text { consecutive items pass } \\
\text { inspection, shift to Level } 2 .\end{array}$ & $\begin{array}{l}\text { If the next four items pass } \\
\text { inspection, shift to State } 2 * \text {. }\end{array}$ \\
\hline $\begin{array}{l}\text { If a defect is found, } \\
\text { shift to State } 1 \mathrm{R} .\end{array}$ & $\begin{array}{l}\text { If a defect is found, } \\
\text { shift to } 100 \% \text { Level. }\end{array}$ & $\begin{array}{l}\text { If a defect is found before four items } \\
\text { pass inspection, shift to } 100 \% \text { Level. }\end{array}$ \\
\hline $\begin{array}{r}\text { Inspec } \\
\text { When } 1\end{array}$ & $\begin{array}{l}\% \text { of all certified production by } \\
\text { nsecutive items pass inspection, }\end{array}$ & $\begin{array}{l}\text { e technician. } \\
\text { ift to Level } 1 .\end{array}$ \\
\hline
\end{tabular}

Fig. 1. Multistage inspection policy.

$S_{j}: \quad$ Inspection rate $\%$ of each technician based on his current level.

$E_{j}: \quad$ Expected failures.

$E$ : Total expected failures.

$M: \quad$ Failure rate of the facility.

$n_{L}: \quad$ Number of technicians at level $L$.

$A_{j}$ : Average failure rate of class $j$ where $j=0,1, \ldots, 4$.

$V_{j}$ : QVI (Quality Verification Inspection) for technician $j$ (inspection to verify device calibration quality).

$Q_{L}: \quad$ Total QVI at level $L$.

$Q: \quad$ Total QVI.

AOQa: The actual average outgoing quality.

AOQq: The average outgoing quality computed from the QVI.

AOQl: The actual average outgoing quality computed from levels only.

AOQ: Reported average outgoing quality.

Two methods will be presented to calculate the AOQ of the calibration facility that is using the above-mentioned inspection method. The two methods will be called as the QVI based AOQ method and the Technician based AOQ method.

\subsection{QVI based AOQ method}

Based on the definitions of the notations, the total production is:

$$
T=\sum_{j=1}^{C} P_{j} .
$$

The inspection rate $\%$ at level $j$ is:

$$
S_{j}=\frac{100}{2^{j}} \quad \text { for } \quad j=1 \text { to } L
$$

Therefore, the total QVI is (the double square brackets indicate that the value enclosed is rounded up to the next integer):

$$
Q=\sum_{j=1}^{C} V_{j}=\sum_{j=1}^{C} \llbracket \frac{P_{j} S_{j}}{100} \rrbracket .
$$


The total expected failures are:

$$
E=\sum_{j=1}^{C} R_{j} V_{j}=\sum_{j=1}^{C} R_{j} \llbracket \frac{P_{j} S_{j}}{100} \rrbracket .
$$

Therefore, the failure rate of the facility is:

$$
M=\frac{E}{Q} .
$$

and the AOQq is given by:

$$
A O Q q=0.9375-\frac{(T-Q) M}{T} .
$$

The reason for using 0.9375 instead of one is that the best technician will still have $6.25 \%$ of his work inspected leaving him with $93.75 \%$ uninspected, which can be rounded to $95 \%$ if we take $80 \%$ of the $6.25 \%$, i.e. $5 \%$ as the actual inspection rate for the best technicians. Hence the AOQq will then be calculated by:

$$
A O Q q=0.95-\frac{(T-Q) M}{T} .
$$

\subsection{Technician based AOQ method}

The failure rates of all technicians are assumed to be less than or equal to $20 \%$. This is the basic requirement of a technician qualification. Any technician who has a failure rate of more than $20 \%$ must not join the production. Based on this fact, since there are five levels, we may assume that the failure rate of all technicians can be classified to five classes of failure rates that are equally spaced.

The classes would then be:

- From $16 \%$ to $20 \%$ for those in level 0 with an average failure rate of $18 \%$, thus $A_{0}=0.18$.

- From $12 \%$ to $16 \%$ for those in level 1 with an average failure rate of $14 \%$, thus $A_{1}=0.14$.

- From $8 \%$ to $12 \%$ for those in level 2 with an average failure rate of $10 \%$, thus $A_{2}=0.10$.

- From $4 \%$ to $8 \%$ for those in level 3 with an average failure rate of $6 \%$, thus $A_{3}=0.06$.

- From $0 \%$ to $4 \%$ for those in level 4 with an average failure rate of $2 \%$, thus $A_{4}=0.02$.

Therefore, any technician at level 4 would be assumed to have a failure rate of 0.02 no matter what his actual failure rate is. So do all the technicians at other levels, each of them would be assumed to have the average failure rate of the class corresponds to his level. The logic behind relies on the following assumptions:

1) It is very likely that the technician with a higher level will have a lower class, and very unlikely to be otherwise. The inspection process will likely spot the discrepancies and the technician level will be quickly adjusted.
2) Technicians' failure rates are uniformly distributed over the classes (because there is no known bias that makes them otherwise).

3) Technicians' failure rates within the class are also uniformly distributed for the same reason and therefore the average is a good representative of each technician failure rate.

The total production of all technicians is again:

$$
T=\sum_{j=1}^{C} P_{j}
$$

This leads to the QVIs (number of items subjected to inspection) at level $L$ is:

$$
Q_{L}=\frac{100}{2^{L}} \sum_{i=1}^{n_{L}} P_{L i}
$$

The average production per technician at level $L$ is:

$$
X_{L}=\frac{\sum_{i=1}^{n_{L}} P_{L i}}{n_{L}}
$$

The average production per technician at various levels, in general, can safely be assumed to equal (i.e. $X_{1}=X_{2}=$ $\left.X_{3}=X_{4}\right)$. This is due to the fact that in most calibration labs it is a primary objective to distribute work evenly between technicians. Therefore, the following formula holds at all time:

$$
X=X_{1}=X_{2}=X_{3}=X_{4}
$$

$Q_{L}$ can thus be rewritten as:

$$
Q_{L}=S_{L} n_{L} X_{L}
$$

This gives the total QVI as:

$$
Q=\sum_{L=1}^{4} Q_{L}=\sum_{L=1}^{4}\left(S_{L} n_{L} X_{L}\right)=X \sum_{L=1}^{4}\left(S_{L} n_{L}\right)
$$

This makes the total number of failures as:

$$
E=\sum_{L=1}^{4} S_{L} n_{L} X_{L} A_{L}=X \sum_{L=1}^{4} S_{L} n_{L} A_{L} .
$$

The general failure rate of the facility is thus:

$$
M=\frac{E}{Q}=\frac{\sum_{L=1}^{4}\left(S_{L} n_{L} A_{L}\right)}{\sum_{L=1}^{4}\left(S_{L} n_{L}\right)} .
$$

This leads to:

$$
A O Q l=\frac{(T-Q) M}{T} .
$$




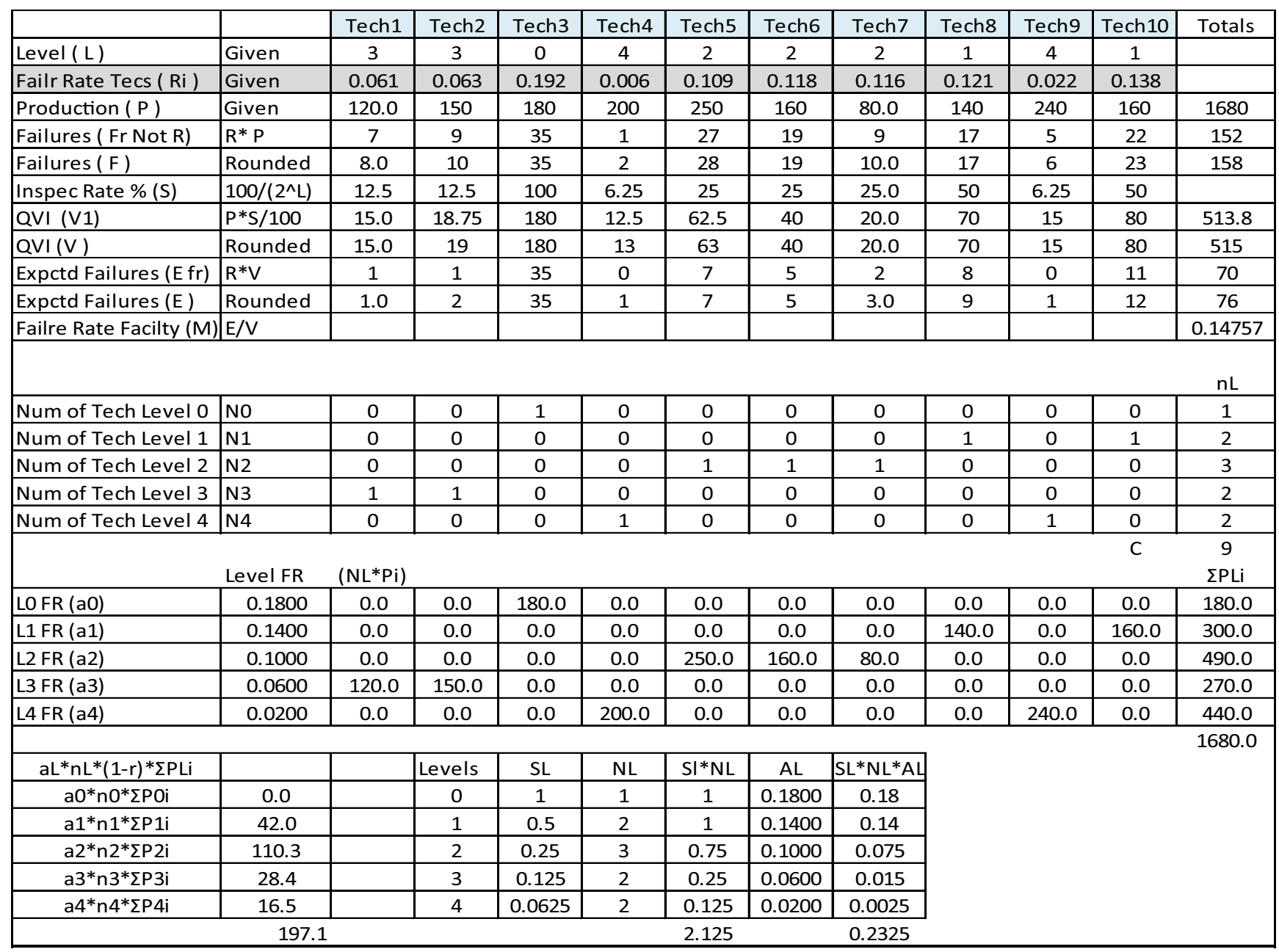

Fig. 2. Simulation results.

Since the total production based on the above argument can be rewritten as $T=C X$, we have:

$$
\begin{aligned}
A O Q l & =0.95-\frac{\left(C X-X \sum_{L=1}^{4}\left(S_{L} n_{L}\right)\right) M}{C X} \\
& =0.95-\left[M-\frac{M \sum_{L=1}^{4}\left(S_{L} n_{L}\right)}{C}\right] \\
& =0.95-\left(\sum_{L=1}^{4}\left(S_{L} n_{L} A_{L}\right)\right)\left(\frac{1}{\sum_{L=1}^{4}\left(S_{L} n_{L}\right)}-\frac{1}{C}\right) .
\end{aligned}
$$

\section{Method validation}

In order to validate the use of the two methods developed, they must be verified against an actual production system with known technician failure rates. A simulation is performed to compare the two method's performance with the preset failure rates.

\begin{tabular}{|l|c|}
\hline AOQ Actual & 0.9094 \\
\hline AOQ W QVI & 0.8477 \\
\hline AOQ W levels only & 0.8664 \\
\hline
\end{tabular}

Fig. 3. Computed values of the AOQ from the simulation.

\subsection{Simulation}

The simulation is constructed in an Excel worksheet shown in Figure 2. All the parameters and the intermediate steps are shown in the order of the simulation.

The AOQ of the actual and those given by the two methods are shown in Figure 3.

The results of 30 runs are shown in Figure 4 along with the average values of the actual and the two methods computed from the 30 runs.

\subsection{Comparison}

The two methods are compared in the above simulation with the actual value of the AOQ. Both are found to be very effective and they do not differ from the actual value 


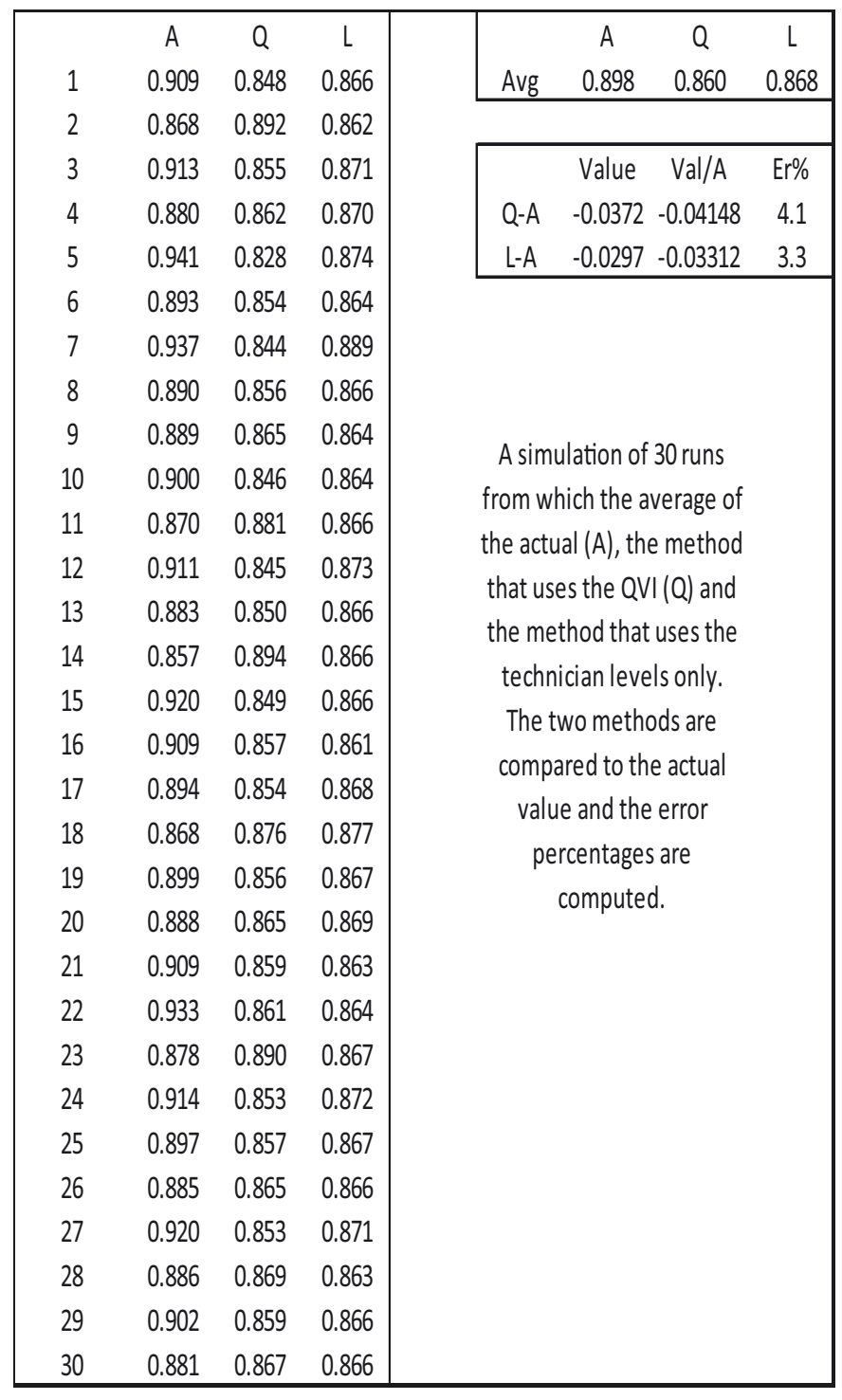

Fig. 4. 30 simulated runs of the AOQ.

by more than $5 \%$ in most cases. Method 1 is used when there is a need to utilize the outcome of the QVIs and the number of failures. Method 2 is useful when there is a need to quickly find the AOQ without waiting for the outcome of the inspections to be complete. Method 2 can be evaluated in a matter of seconds because it requires only the number of technicians at each level. These numbers may not change quickly, and consequently the calculation of AOQ would be performed with the change of a number or two. It can also be said that the AOQ is unchanged as long as there is no change in the number of technicians at each level (although there might be changes in individual technician's levels).

\section{Discussion}

The impact of knowing the calibration facility's AOQ on the system performance is considered to be an efficiency driver. Knowing the value is not so much the goal, what is more important is the method by which this value is arrived at. The method of assessing the AOQ of the system is the primary objective and for that matter the development of this method depends entirely on the inspection policy used in the system.

The impacts on the system are as follows:

- Completion of the feedback cycle to establish a full production controlled loop which allows for the addition of some corrective measure continuously.

- Knowledge of the size of the defective items that leave the system.

- May allow for the establishment of quality control chart that alert the facility when the quality is drastically declining.

- Depending on the method, it may allow for tracing back the source generating more defective items than normal.

- Help the engineers and top management to develop quality improvement policy and monitor their progress.

- Stop any developed defective items streak that may happen due to various reasons (for instance a newly assigned operator or a newly bought instrument).

Although the inspection and AOQ as a detection oriented approach will not directly improve the production quality and indeed, current emphasis in quality management has been on process and/or design oriented approaches (e.g. SPC, QFD, Poka Yoke), the use of the multistage inspection policy and AOQ may indirectly result in quality improvement through economic and psychological pressures of non-acceptance or failures [10]. They may also be used together with other prevention oriented QC/QA techniques, e.g. SPC.

\section{Conclusions}

In conclusion, the two methods developed to calculate the AOQ and, in particular, the technician based AOQ method (Method 2) are quite useful and they can provide the quality assurance inspectors, the lab internal management and the facility top management with an excellent assessment of the lab AOQ. It also helps the QA personnel to quickly react to any sudden decrease in service quality before a large number of bad items leave the facility. This advantage is of particular interest to the customers since it assures them that only a small number of un-calibrated items may really be allowed to reach them.

It is likely that the proposed multistage inspection policy and the use of $\mathrm{AOQ}$ can indirectly result in quality improvement through better motivation and psychological pressures. They can also be used together with other prevention oriented techniques and play a significant role in practical quality management. 


\section{References}

1. E.B. Jamkhaneh, B.S. Gildeh, AOQ and ATI for double sampling plan with using fuzzy binomial distribution, Proc. of the 2010 International Conference on Intelligent Computing and Cognitive Informatics, pp. 45-49

2. N.R. Farnum, Closed-form approximation for the AOQL of attributes acceptance sample plans, Commun. Stat. Simulation Comput. 35, 1057-1065 (2006)

3. S. Balamurali, C.H. Jun, Average outgoing quality of CSP-C continuous sampling plan under short run production processes, J. Appl. Stat. 33, 139-154 (2006)

4. H.F. Yu, W.C. Yu, An optimal mixed policy of inspection and burn-in and the optimal production quantity, Int. J. Prod. Econ. 105, 483-491 (2007)

5. G.L. Yang, A renewal-process approach to continuous sampling plans, Technometrics 25, 59-67 (1983)
6. G.L. Yang, A renewal look at switching rules in the MILSTD-105D sampling system, J. Appl. Probab. 27, 183-192 (1990)

7. H.C. Yeh, H.T. Tsai, M.C. Yu, Design of one-sided screening specifications for multi-characteristic product, First International Conference on Innovative Computing, Information and Control (ICICIC'06) (2006), Vol. 2, pp. $482-485$

8. H. Moskowitz, H.T. Tsai, A one-sided double screening procedure using individual unit misclassification error, Manag. Sci. 34, 1139-1153 (1988)

9. N.S. Fard, J.J. Kim, Analysis of two stage sampling plan with imperfect inspection, Comput. Ind. Eng. 25, 453-456 (1993)

10. ISO 2859-10, Sampling procedure for inspection by attribute (2006) 